\title{
Manufactures Animal Over-the-Counter Drugs
}

National Cancer Institute

\section{Source}

National Cancer Institute. Manufactures Animal Over-the-Counter Drugs. NCI

Thesaurus. Code C114891.

A business that makes non-prescription veterinary drugs. 